\title{
Advances in Chromatography and Electrophoresis 2018 and Chiranal 2018
}

\section{Jan Petr ${ }^{1}$}

Published online: 18 July 2018

(c) Springer-Verlag GmbH Germany, part of Springer Nature 2018

The traditional international conference "Advances in Chromatography and Electrophoresis 2018 \& Chiranal 2018" took place in Olomouc, Czech Republic, from January 29 th to February 1st. The conference was organized at the
Regional Centre of Advanced Technologies and Materials, Palacký University in Olomouc by the Department of Analytical Chemistry and the Working Group of Chromatography and Electrophoresis of the Czech Chemical Society.

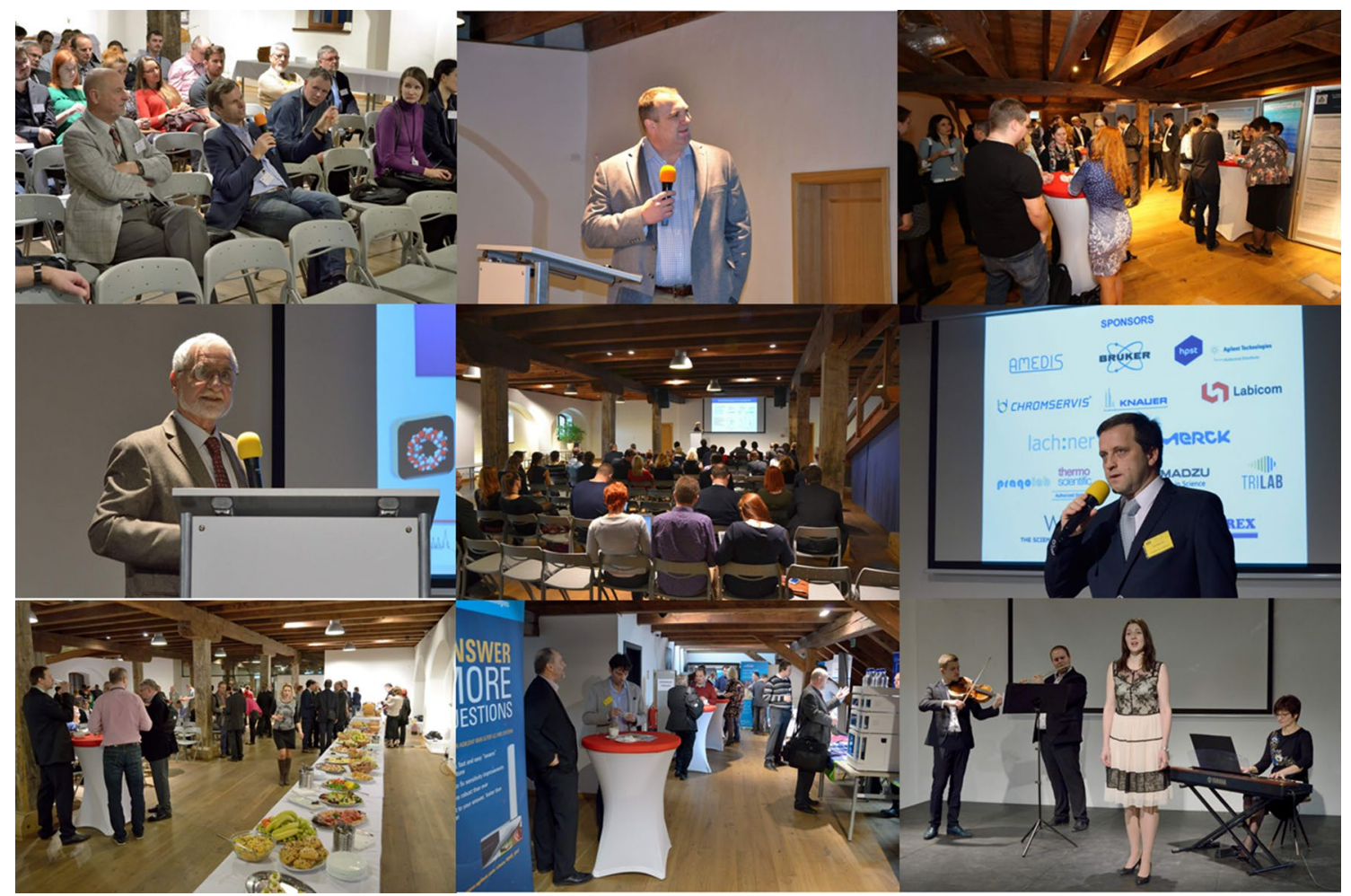

Published in the topical collection Advances in Chromatography and Electrophoresis \& Chiranal 2018 with guest editor Jan Petr.

\section{Jan Petr \\ secjpetr@gmail.com}

1 Department of Analytical Chemistry, Faculty of Science,

Regional Centre of Advanced Technologies and Materials, Palacký University in Olomouc, Olomouc, Czech Republic 
The scientific program started with a great plenary lecture "Recent advancements in chiral separations using miniaturized techniques" given by Prof. Fanali (Rome, Italy). Next day, the program continued with interesting themes and speakers such as Prof. Lämmerhofer (Tübingen, Germany), Prof. Švec (Hradec Králové, Czech Republic), Prof. Roth (Brno, Czech Republic), Prof. Nováková (Hradec Králové, Czech Republic), Prof. Kubán (Brno, Czech Republic), Prof. Hutta (Bratislava, Slovakia) or Prof. Kašička (Prague, Czech Republic). The conference ending was marked by a magnificent plenary lecture by Prof. Schug (Arlington, TX) "The vacuum ultraviolet spectroscopy toolkit for gas chromatography detection". In addition to these, the program consisted also of many lectures and poster presentations presented by young researchers and students who demonstrated their interest in doing great science.
Finally, we thank all the authors for their interesting contributions, participants attending the symposium and sharing their great ideas, all the companies who supported the symposium, all the people who organized the conference, all reviewers for evaluation of the papers, the Chromatographia editors, and the Chromatographia team for the preparation of this issue. Last but not least, we acknowledge the support of the Regional Centre of Advanced Technologies and Materials and the Palacký University in Olomouc, Czech Republic.

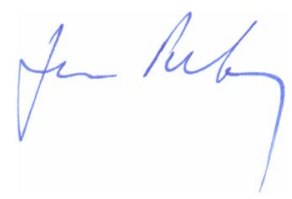

Jan Petr 